Article

\title{
Thermal Boundary Characteristics of Homo-/Heterogeneous Interfaces
}

\author{
Koen Heijmans ${ }^{1}$ (), Amar Deep Pathak ${ }^{1}{ }^{(0)}$, Pablo Solano-López ${ }^{2}$, Domenico Giordano ${ }^{3}$, \\ Silvia Nedea ${ }^{1, *}$ and David Smeulders ${ }^{1}$ \\ 1 Energy Technology, Department of Mechanical Engineering, Eindhoven University of Technology, \\ 5600 MB Eindhoven, The Netherlands; k.heijmans@tue.nl (K.H.); simplyamar06@gmail.com (A.D.P.); \\ d.m.j.smeulders@tue.nl (D.S.) \\ 2 Departmento de Fisica Aplicada, ETSIAE, Universidad Politécnica de Madrid, 28040 Madrid, Spain; \\ Pablo.Solano@upm.es \\ 3 ESA-Estec, Keplerlaan 1, 2201 AZ Noordwijk, The Netherlands; dg.esa.retired@gmail.com \\ * Correspondence: s.v.nedea@tue.nl
}

Received: 15 March 2019; Accepted: 19 April 2019; Published: 26 April 2019

check for updates

\begin{abstract}
The interface of two solids in contact introduces a thermal boundary resistance (TBR), which is challenging to measure from experiments. Besides, if the interface is reactive, it can form an intermediate recrystallized or amorphous region, and extra influencing phenomena are introduced. Reactive force field Molecular Dynamics (ReaxFF MD) is used to study these interfacial phenomena at the (non-)reactive interface. The non-reactive interfaces are compared using a phenomenological theory (PT), predicting the temperature discontinuity at the interface. By connecting ReaxFF MD and PT we confirm a continuous temperature profile for the homogeneous non-reactive interface and a temperature jump in case of the heterogeneous non-reactive interface. ReaxFF MD is further used to understand the effect of chemical activity of two solids in contact. The selected $\mathrm{Si} / \mathrm{SiO}_{2}$ materials showed that the TBR of the reacted interface is two times larger than the non-reactive, going from $1.65 \times 10^{-9}$ to $3.38 \times 10^{-9} \mathrm{~m}^{2} \mathrm{~K} / \mathrm{W}$. This is linked to the formation of an intermediate amorphous layer induced by heating, which remains stable when the system is cooled again. This provides the possibility to design multi-layered structures with a desired TBR.
\end{abstract}

Keywords: ReaxFF; interface; thermal boundary resistance; Kapitza resistance

\section{Introduction}

Molecular characteristics of solids in contact play a key role in various fundamental studies related to heat transfer [1], mechanical behavior [2], micro/nano-fluidics [3], and catalysis [4]. Besides, it plays an important role in applications related to semiconductors [5], microelectronics [6,7] and heat-shielding in re-entry vehicles for aerospace applications [8]. In the latter case, insight into the thermal resistance at an interface of a multilayer structure is crucial for prediction and control of overheating of the thermal protection system used for the re-entry shuttle. The non-equilibrium effects of a hypersonic flow impinging on a solid interface requires detailed investigation of the boundary processes. Mass, momentum, energy transfer and chemical reactions on the interface are critical under these extreme conditions [9]. These processes can change the interfacial properties significantly compared to initial bulk properties. Furthermore, in case of chemical reactions at the interface (as shown in Figure 1), insight into the heat transfer in a small layer of material (a few molecular layers) is required. 


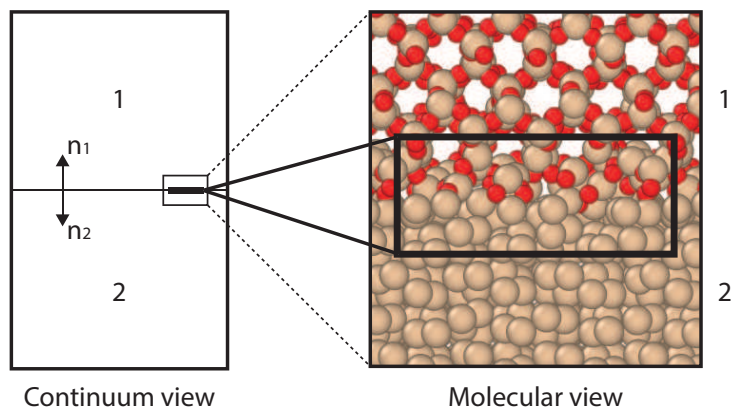

Figure 1. A schematic representation of continuum and molecular view of a system chosen for the present study.

The influence of the solid interfaces on thermal properties can be analyzed by the local temperature profiles on a molecular level. Experimental measurement of a temperature profile at the molecular level is extremely challenging. Therefore, computational models can be useful accurate tools to provide thermal insight and to establish the interfacial thermal correlations. In the context of building up a macroscopic theory of gas-surface interactions targeting the hypersonic re-entry flows, Giordano et al. [8] have proposed a Phenomenological-Theory (PT) to study heat transfer between two solids in contact. Another tool is Molecular Dynamics (MD) simulations, which has been used before to investigate thermal transport across solid interfaces [10-16], and significant influences of the solid interface on the thermal conduction are reported. A schematic representation of these two methods is shown in Figure 1, with a continuum view for PT, and a molecular view for ReaxFF.

Though temperature profiles at the solid interface are investigated before, these studies and methods focus mainly on non-reactive interfaces. However, chemical activity at the interfaces can influence the thermal behavior of solids in contact. Therefore, reactive force field Molecular Dynamics (ReaxFF $[17,18]$ ) is used, which is able to capture the chemical reaction and its influence on the surface transformation and temperature profile on molecular level.

In this study, we first consider the characterization of material properties like thermal expansion, thermal conductivity, and elastic properties using ReaxFF, to validate the force field. Thereafter, we build a generic non-reactive system, in which an interface is created based on the same material, for this, we considered two Platinum slabs (homogeneous $\mathrm{Pt} / \mathrm{Pt}$ interface). Further, we create an interface between two different materials in contact, a non-reactive heterogeneous Platinum-Nickel interface (Pt/Ni). Accordingly, the temperature profiles from the ReaxFF MD simulations are compared with the macroscopic level PT based model of Giordano et al. [8]. For the computation of the temperature profile with PT, relevant material properties are computed with ReaxFF MD and upscaled, to be used as input in the PT model. Platinum and Nickel were selected because they are well studied, non-reactive, monatomic, and have similar lattice size.

After we analyzed this generic model, we created the reactive heterogeneous interface of Silicon and Silicon-oxide $\left(\mathrm{Si} / \mathrm{SO}_{2}\right)$. This $\mathrm{Si} / \mathrm{SiO}_{2}$ interface is of relevance for many applications in the semiconductor industry, as well as aerospace engineering [19]. Because of its relevance, the $\mathrm{Si} / \mathrm{SiO}_{2}$ interface is studied numerous times before [20], including the thermal boundary resistance (TBR) based on experiments [21], or numerical methods like MD [12-14], acoustic and diffusive mismatch models (AMM, DMM) [22], and phonon wave-package method [12]. With ranging values between 0.4-3.5 $\times 10^{-9} \mathrm{~m}^{2} \mathrm{~K} / \mathrm{W}$, depending on the method and composition of the materials. Furthermore, Chen et al. showed a strong correlation between the coupling between the materials and the TBR. These coupling can be directly related to reactions happening at the interface. However, to our knowledge no systematic studies has been done on the influence of a reactive interface on the TBR. Therefore, we used ReaxFF to study the influence of the reactive interface. The $\mathrm{Si} / \mathrm{SiO}_{2}$ system is kept at various temperatures, within the ReaxFF simulations, to increase/decrease the chemical activity. Accordingly, the TBR is computed. The TBR is defined as the temperature discontinuity at the interface $(\Delta T)$ divided 
by the heat flux $(Q)$ that crosses the interface, see Equation (1). The TBR is often referred as the Kapitza resistance [23], however, we kept the analogy of Peterson et al. [24]:

$$
T B R=R=\Delta T / Q
$$

\section{Methodology \& Material Properties Estimation}

\subsection{Phenomenological-Theory (PT)}

To study the heat transfer between two solids in contact, Giordano et al. [8] have proposed a Phenomenological-Theory (PT). With the aim of building up a macroscopic theory of gas-surface interactions targeting the hypersonic re-entry flows. They have remarked the lack of a physical principle justifying the standard temperature-continuity boundary conditions as a replacement of temperature-continuity, and have introduced tension continuity:

$$
\mathbf{n}_{1} \cdot \tau_{U, 1}(P, t)+\mathbf{n}_{2} \cdot \tau_{U, 2}(P, t)=0
$$

where, $\mathbf{n}_{1}$ and $\mathbf{n}_{2}$ are normal unit vectors at a point of contact $P$ and time $t$. This macroscopic theory is founded on momentum conservation and represents a more physically motivated boundary condition. For the mathematical formulation of the phenomenological-theory and further details, readers can refer to the original paper [8]. This method is used to compare the temperature profile non-reactive interfaces studied with MD. For the input of required material properties, the MD calculated values are used.

\subsection{Reactive Force Field Molecular Dynamics}

Molecular Dynamics (MD) is a computational method to obtain macroscopic and microscopic properties from approximated trajectories of individual particles. These approximated trajectories, obtained from Newton's equations of motion, form an ensemble from which macroscopic properties of materials can be obtained [25]. To capture the chemical change during a reaction, Reactive force field (ReaxFF) [17] is used. ReaxFF is computationally more expensive than the non-reactive force field, however, it allows bond formation and bond breaking during the simulations, which makes simulations of chemical reactions possible. According to ReaxFF the bond order between a pair of atoms can be obtained directly from the inter-atomic distance, which relation is used to mimic chemical change. The feature of bond formation and breaking allows the user not to give predefined reactions pathways, these should present themselves given the right temperatures and chemical environment. However, the accuracy of this relies directly on the training set and the weights that are used to parameterize the reactive force field. Therefore, we tested several available ReaxFF on their ability to predict relevant material characteristics for our study. ReaxFF is widely used in studying chemical activities at a molecular level $[18,26]$, including many $\mathrm{Si} / \mathrm{SiO}_{2}$ systems $[19,20,27-35]$.

For the in-silico characterization using ReaxFF MD methodology, we compute the material properties of relatively simple systems of Platinum (Pt), Nickel (Ni), Silicon (Si) and Silicon dioxide $\left(\mathrm{SiO}_{2}\right)$. Furthermore, the elastic properties, thermal expansion coefficient, and thermal conductivity of the materials are important parameters for the phenomenological-theory, and thus the computed values are used as input parameters to upscale the molecular results up to the macroscopic level.

\subsubsection{Force Field Selection}

Selection of an appropriate force field is very important for in-silico characterization. The calculations of elastic properties, thermal expansion coefficients and the radial distribution function $(\mathrm{RDF})$, guide as a selection criterion for the appropriate force fields. Supercells of $(5 \times 5 \times 5) \mathrm{Pt}$, $(5 \times 5 \times 5) \mathrm{Ni},(3 \times 3 \times 3) \mathrm{Si}$ and $(4 \times 4 \times 4) \mathrm{SiO}_{2}$ are created, containing approximately $400-800$ atoms, with initial volumes of 7547, 5469, 7890, and $10,913 \AA^{3}$, respectively. Periodic Boundary Conditions 
(PBC) are applied in all directions. The unit cells of $\mathrm{Pt}$ [36], Ni [37], $\mathrm{Si}$ [38] and $\mathrm{SiO}_{2}$ [39] are taken from experimental crystallographic information files.

We have chosen three reactive force fields $[4,29,40]$ available for $\mathrm{Pt}$ and $\mathrm{Ni}$ and nine force fields for $\mathrm{Si}$ and $\mathrm{SiO}_{2}$ [19,29-35]. These force fields are tested by deforming the crystals in the range of 0.86 to 1.16 times their initial volume. The resulting increase in potential energy is shown in Figure 2.
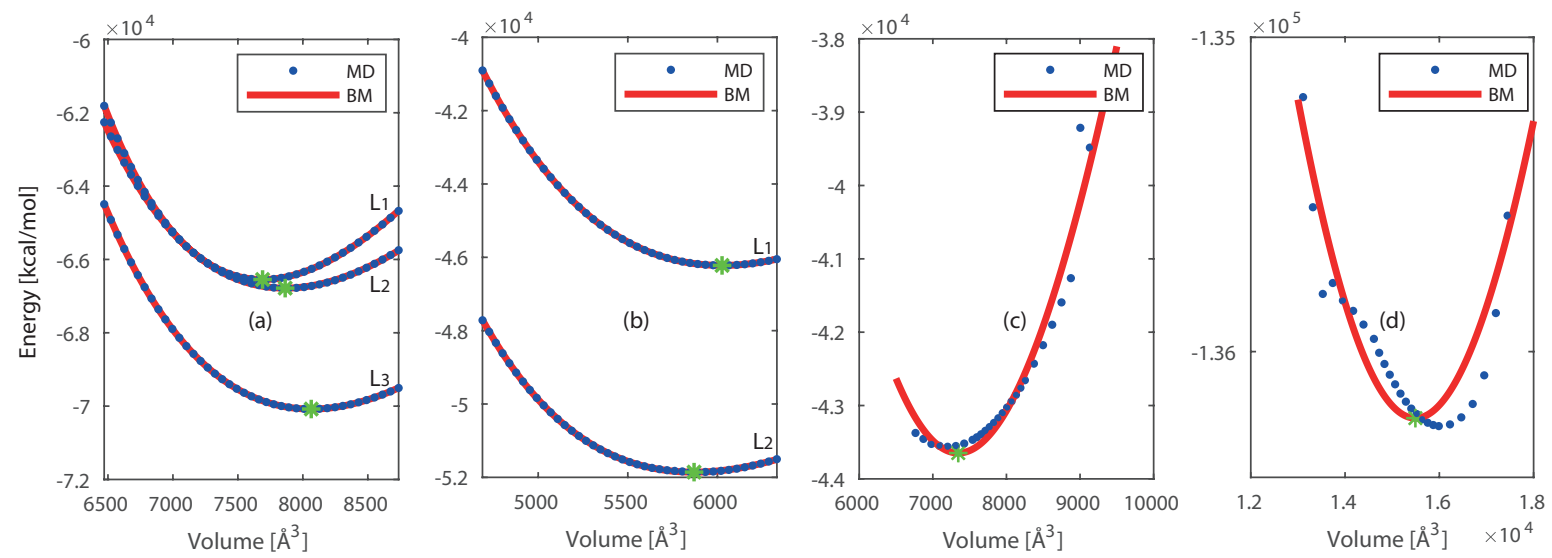

Figure 2. The energy of system obtained from selected force fields as a function of volume and the fitted BM-eos for: (a) $5 \times 5 \times 5 \mathrm{Pt}$, (b) $5 \times 5 \times 5 \mathrm{Ni}$, (c) $3 \times 3 \times 3 \mathrm{Si}$, and (d) $4 \times 4 \times 4 \mathrm{SiO}_{2}$. The ' $\star$ ' represents the minimum energy point $\left(E_{0}, V_{0}\right)$ on each curve.

For clarity only the best performing force field is shown for $\mathrm{Si}$ and $\mathrm{SiO}_{2}$. The relation between volume and energy is found by integration of the pressure in the third order Birch-Murnaghan equation of state (BM-eos) [41-43], this relation is fitted to the results of the deformed crystal. The resulting parameters $\left(B_{0}\right.$ and $\left.V_{0}\right)$ are given in Appendix $A$ and compared with the literature.

The force field developed by J.E. Mueller et al. [4] showed the best results, and was therefore chosen for further use including $\mathrm{Pt}$ and $\mathrm{Ni}$. This force field was parameterized for studying hydrocarbon reactions on nickel surfaces. They included the equation of state (EOS) for different Ni bulk structures in the training. Both our and their calculations predicted the EOS, together with the lattice parameters, in close agreement with quantum mechanical calculations. We predicted the equilibrium volume $\left(V_{0}\right)$ of $\mathrm{Pt}$ [36] and $\mathrm{Ni}$ [37] unit cells within $1.9 \%$ and $7.0 \%$ deviations from their experimentally observed crystal structures. The deviations for the bulk modulus $\left(B_{0}\right)$ of $\mathrm{Pt}$ and $\mathrm{Ni}$ are $9.8 \%$ [44] and 16.0\% [45] respectively. Furthermore, Mueller et al. computed cohesive energies in close agreement with experimental values. The force field developed by Kulkarni et al. [19] was chosen for further use including $\mathrm{Si}$ and $\mathrm{SiO}_{2}$. This force field is an extension to include gas-surface reactions between oxygen and silica into an existed force field developed by van Duin et al. [20]. This original force field was parametrized to include the chemistry of silicon and silicon oxides, and the interface between these materials. Previous work of Tian et al. [46] also indicated that this original force field predicts the thermal conductivity of vitreous $\mathrm{SiO}_{2}$ in close agreement with experimental values. The force field of Kulkarni et al. is able to predict the equilibrium volume $\left(V_{0}\right)$ within $7.5 \%$ [38] and $30 \%$ [39] deviations for $\mathrm{Si}$ and $\mathrm{SiO}_{2}$, respectively. The bulk modulus $\left(B_{0}\right)$ is within $22.9 \%$ [47] and $5.7 \%$ [48] deviations for $\mathrm{Si}$ and $\mathrm{SiO}_{2}$, respectively. Therefore, this force field is selected for the study that includes $\mathrm{Si}$ and $\mathrm{SiO}_{2}$. These force fields are chosen for further investigation.

To validate further the applicability of the chosen force fields, we have obtained the Radial Distribution Functions (RDFs) of $\mathrm{Pt}-\mathrm{Pt}, \mathrm{Ni}-\mathrm{Ni}$, $\mathrm{Si}-\mathrm{Si}\left(\mathrm{Si}\right.$ and $\left.\mathrm{SiO}_{2}\right)$ and $\mathrm{Si}-\mathrm{O}\left(\mathrm{SiO}_{2}\right)$ pairs from $\mathrm{ReaxFF}$ MD simulations in periodic solid supercells as shown in Figure 3. 


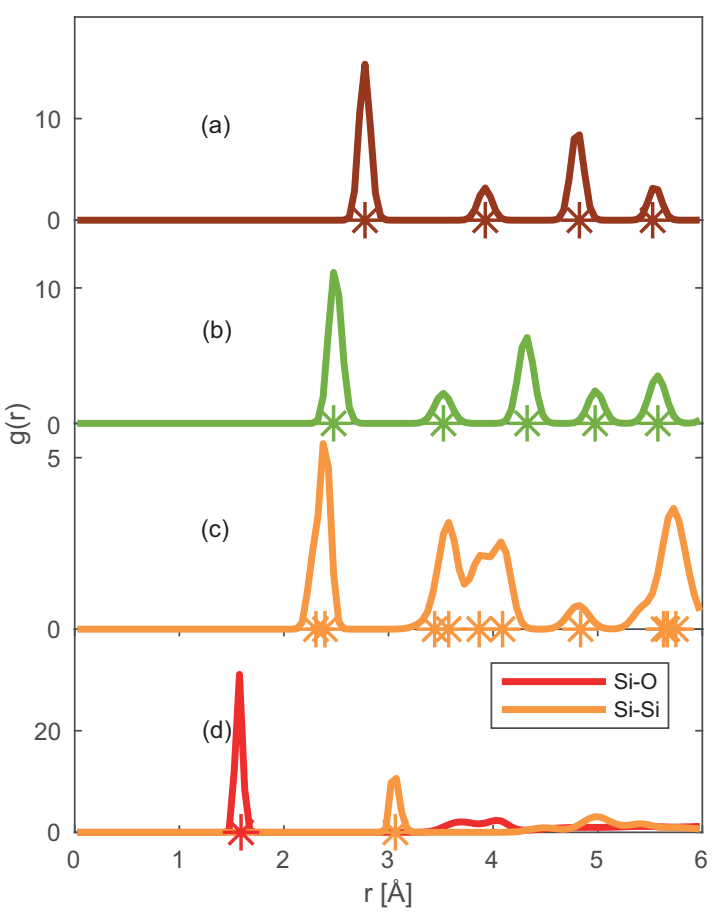

Figure 3. Radial distribution functions for: (a) $\mathrm{Pt}-\mathrm{Pt}$, (b) $\mathrm{Ni}-\mathrm{Ni}$, (c) $\mathrm{Si}-\mathrm{Si}$ and (d) $\mathrm{Si}-\mathrm{O}$ pairs present in studied solid crystals obtained from the ReaxFF MD simulations. The '*' represents the neighboring atomic distances inside the solid crystal. For clarity, only the nearest neighbor ' $*$ ' is shown in $\mathrm{SiO}_{2}$.

The sharp peaks in RDF elucidate the extent of ordering in the supercell, thus representing the solid phase. The locations of the peaks coincide with the position of neighboring atoms (represented by ' $*^{\prime}$ ) in the experimentally observed solid crystal [36-39]. Concluding that the selected force fields $[4,19]$ can capture the crystalline phase of $\mathrm{Pt}, \mathrm{Ni}, \mathrm{Si}$, and $\mathrm{SiO}_{2}$.

The volumetric thermal expansion coefficient $\left(\alpha_{v}\right)$ can be obtained from the slope of the natural logarithm of the volume $(\ln V)$ versus imposed temperature (T) [49]:

$$
\alpha_{v}=\frac{1}{V}\left(\frac{\partial V}{\partial T}\right)_{p}=\left[\frac{\partial \ln (V)}{\partial T}\right]_{p}
$$

where $\alpha_{v}$ is the volumetric thermal expansion coefficient at constant pressure. We have varied the temperature over $250-500 \mathrm{~K}$ at atmospheric pressure in an NPT ensemble. The thermal expansion coefficients for $\mathrm{Pt}$ and $\mathrm{Ni}$ computed from ReaxFF MD and existing literature values are given in Table 1 . The results on the molecular scale are in reasonable agreement with the bulk experimental value $[50,51]$.

Table 1. Comparison of volumetric expansion coefficients $\left(\alpha_{v}\right)$ obtained from the present ReaxFF MD simulations, and reported from literature (in parentheses).

\begin{tabular}{cc}
\hline Element & $\boldsymbol{\alpha}_{v} \times \mathbf{1 0}^{-\mathbf{5}}\left(\mathbf{m}^{\mathbf{3}} / \mathbf{m}^{\mathbf{3}} \mathbf{K}\right)$ \\
\hline $\mathrm{Pt}$ & $2.0(2.7[50])$ \\
$\mathrm{Ni}$ & $3.2(3.9[51])$ \\
\hline
\end{tabular}

\subsubsection{Thermal Conductivity with Steady State NEMD Method}

The thermal conductivity of a solid can be computed from Steady State Non-Equilibrium Molecular Dynamics (ss-NEMD). This method has been previously used [16,46,52-55], and it is based 
on imposing a temperature gradient over a system to estimate the thermal conductivity. A schematic view of this method is shown in Figure 4.

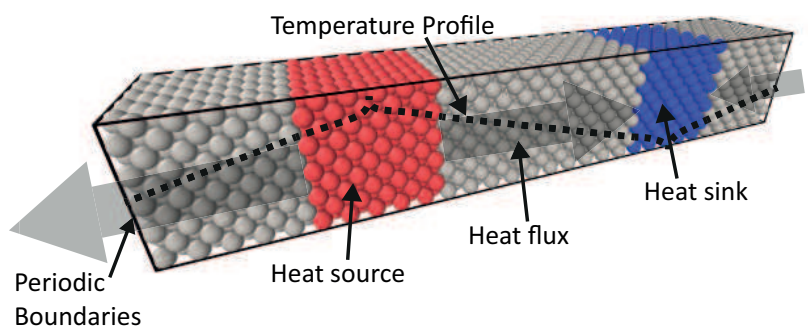

Figure 4. Schematic representation of the chosen system for steady state NEMD simulations. The heat source and sink are coupled to different temperatures with a damping constant of $100 \mathrm{fs}$. This will induce a heat flux through the intermediate zone, which is weakly coupled with a damping constant of $100.000 \mathrm{fs}$.

Two strongly coupled regions (using a Berendsen thermostat with damping constant $\tau=100 \mathrm{fs}$ ) are created, one hot zone (red zone, $T_{H}=330 \mathrm{~K}$ ) and one cold zone (blue zone, $T_{C}=300 \mathrm{~K}$ ), which act as the heat source and sink, respectively. In between these two zones, there are weakly coupled regions (gray zone, $\tau=10^{5} \mathrm{fs}$ ), this damping constant proved to have a negligible low influence on the system. This results in a steady state temperature gradient $(d T / d x)$ and an energy flux $(q)$, in the weakly coupled regions between heat source and sink.

From the energy flux and the temperature gradient, the thermal conductivity $(k)$ can be computed, following Fourier's law. This intuitive principle makes NEMD well suited to study thermal conductivity of different matter, and investigate the influence of structural defects and solid interfaces [52]. According to the kinetic theory, the thermal conductivity $(k)$ is related to the mean free path $(\lambda)$ of energy carriers (Equation (4)). If the characteristic length of the system is larger than the mean free path of carriers, thermal energy is transferred by multiple collisions. In this diffusive regime, the Fourier law is still valid. In cases when the characteristic length of the system is in the order of the mean free path, the energy carriers may travel ballistically between source and sink. This scattering in the heat source and sink introduces an extra limiting effect on the mean free path, and thus a reducing effect on the conductivity (Equation (4)). Thus, the conductivity equation must be corrected for the enhanced scattering effect [56]:

$$
k=\frac{1}{3} C_{v} v \lambda_{L}
$$

where $C_{v}$ is the heat capacity, $v$ the energy carrier velocity, and $\lambda_{L}$ the corrected mean free path for a system of size $L$. This can be estimated from Matthiessen's rule [57], which states that the corrected resistivity is the sum of the intrinsic scattering and the scattering due to impurity. Thus, the corrected mean free path can be expressed as a combined effect of the mean free path of bulk $\left(\lambda_{\infty}\right)$ and length of the system $(L)$ as:

$$
\frac{1}{\lambda_{L}}=\frac{1}{\lambda_{\infty}}+\frac{4}{L}
$$

In a system with periodic boundary conditions, the average distance for an energy carrier to scatter with the heat source or sink is $L / 4$ [16]. Combining Equations (4) and (5), the thermal conductivity $\left(k_{L}\right)$ of system size $L$ can be expressed as:

$$
\frac{1}{k_{L}}=\frac{12}{C_{v} v} \frac{1}{L}+\frac{1}{k_{\infty}}
$$

In this equation, $\frac{1}{k_{\infty}}$ is the thermal conductivity of the bulk material. Bulk thermal conductivity $\left(k_{\infty}\right)$ can be estimated by extrapolating the effective thermal conductivity obtained for small system sizes $\left(k_{L}\right)$. 
The thermal conductivities of $\mathrm{Pt}$ and $\mathrm{Ni}$ are computed using the ss-NEMD method for different system sizes. The total length of the systems varied from $3 \times 3 \times X$ (with $X$ from 24 to 156), including $3 \times 3 \times 6$ zones as the heat source and sink. The energy flux is taken from the average of the heat flux added and extracted by the two strongly coupled regions. The temperature gradient is computed over the weakly coupled region, and the system is equilibrated up to $1 \mathrm{~ns}$ with time steps $(\Delta t)$ of $0.25 \mathrm{fs}$. The by ss-NEMD computed thermal conductivity values are presented in Table 2, and increases with system size for both Pt and Ni systems.

Table 2. Thermal conductivities for different system sizes of Pt and Ni.

\begin{tabular}{ccc}
\hline System & $\begin{array}{c}\text { Conductivity } \\
\mathbf{P t}(\mathbf{W} / \mathbf{m K})\end{array}$ & $\begin{array}{c}\text { Conductivity } \\
\mathbf{N i}(\mathbf{W} / \mathbf{m K})\end{array}$ \\
\hline $3 \times 3 \times 24$ & $4.0 \pm 0.4$ & $7.7 \pm 0.5$ \\
$3 \times 3 \times 36$ & $5.9 \pm 0.3$ & - \\
$3 \times 3 \times 60$ & - & $17.2 \pm 0.6$ \\
$3 \times 3 \times 84$ & $10.4 \pm 0.3$ & $21.7 \pm 0.6$ \\
$3 \times 3 \times 108$ & $15.0 \pm 0.5$ & $24.4 \pm 0.5$ \\
$3 \times 3 \times 132$ & $16.3 \pm 0.3$ & - \\
$3 \times 3 \times 156$ & $19.2 \pm 0.5$ & - \\
\hline Extrapolated & $49.8 \pm 10.5$ & $74.4 \pm 9.2$ \\
Literature & $71.6[58]$ & $90.7[58]$ \\
\hline
\end{tabular}

The thermal conductivities are extrapolated for long length by fitting the linear expression between $1 / L$ and $1 / k$ (Equation (6)) as shown in Figure 5. The fitted lines intersect the $\mathrm{Y}$ axis at $1 / k_{\mathrm{Pt}}=0.021 \mathrm{mK} / \mathrm{W}$ and $1 / k_{\mathrm{Ni}}=0.013 \mathrm{mK} / \mathrm{W}$, which results in a bulk thermal conductivity of $k_{\mathrm{Pt}}=$ $49.8 \pm 10.5 \mathrm{~W} / \mathrm{mK}$ and $k_{\mathrm{Ni}}=74.4 \pm 9.2 \mathrm{~W} / \mathrm{mK}$. The small deviations in an individual system result in large deviations in the bulk thermal conductivity, due to the extrapolation [59]. The computed thermal conductivities are approximately $35 \%$ and $18 \%$ lower than literature [58] values for Pt and $\mathrm{Ni}$, respectively. This was expected because the ReaxFF formalism we used does not describe free electrons. The difference with experimental values can be explained by limitations of the ReaxFF method we used. ReaxFF MD is not able to model free electrons, thereby we underestimate the thermal conductivity. However, our aim is to compare models and confirm the temperature jump, not to compute exactly the thermal conductivities of $\mathrm{Pt}$ and $\mathrm{Ni}$. There is a ReaxFF expansion including free electrons (e-ReaxFF) developed by Islam et al. [60]. At the moment of writing this e-ReaxFF concept does not include the studied materials, nonetheless, this might be interesting for future research.
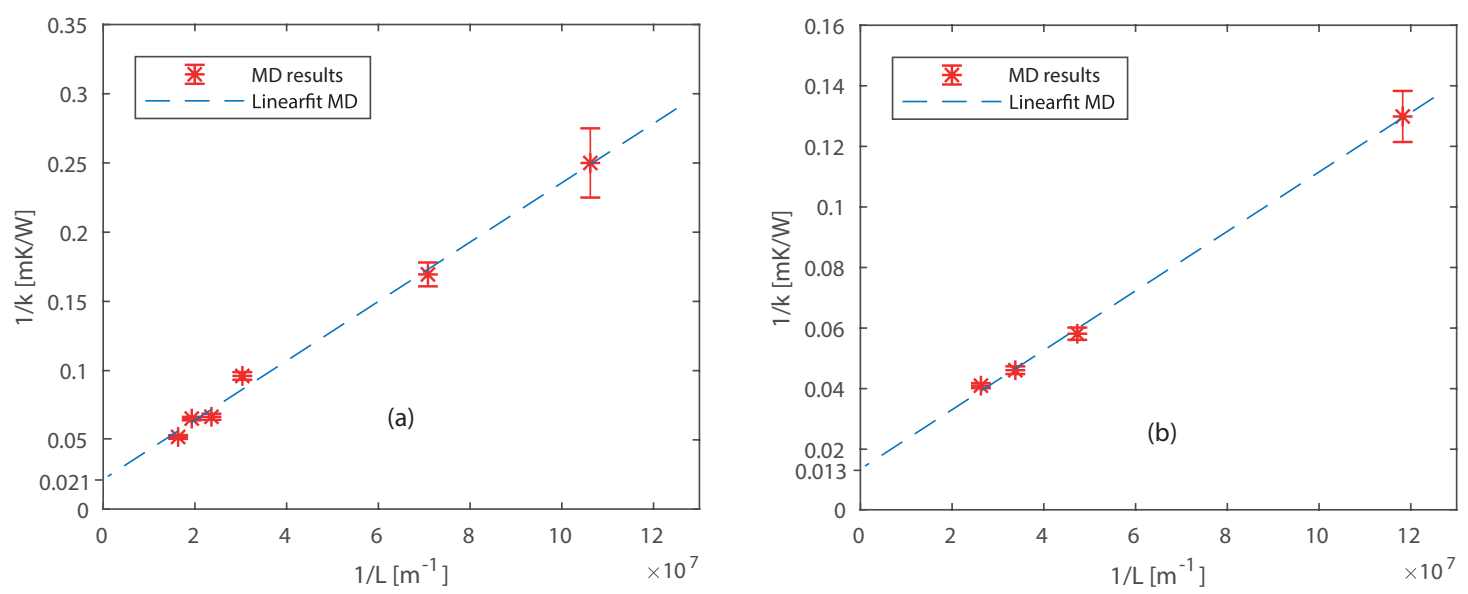

Figure 5. Extrapolation of thermal conductivities for different sizes of (a) Pt and (b) Ni. 
The gradients of the extrapolated curve (Figure 5) obtained from ReaxFF MD simulations are $2.1 \times 10^{-9} \mathrm{~m}^{2} \mathrm{~K} / \mathrm{W}$ and $1.0 \times 10^{-9} \mathrm{~m}^{2} \mathrm{~K} / \mathrm{W}$ for $\mathrm{Pt}$ and $\mathrm{Ni}$, respectively. The gradient should be equal to the theoretical gradient $12 / C_{v} v$ (Equation (6)) obtained from the kinetic theory. By assuming a specific heat of $C_{v, P t}=29 \times 10^{5} \mathrm{~J} / \mathrm{m}^{3} \mathrm{~K}$, and $C_{v, N i}=40 \times 10^{5} \mathrm{~J} / \mathrm{m}^{3} \mathrm{~K}$ [58], the computed velocities of thermal transport carriers are $v_{\mathrm{Pt}} \approx 2 \times 10^{3} \mathrm{~m} / \mathrm{s}, v_{\mathrm{Ni}} \approx 3 \times 10^{3} \mathrm{~m} / \mathrm{s}$. These values are found to be in agreement with the speed of sound in the lateral direction through $\mathrm{Pt}$ and Ni from literature [58]. We also studied the final size effects perpendicular to the heat flow for platinum systems, see Appendix B. However, no finite size effects were observed for perpendicular directions, corresponding to the findings of Zhou et al. [54].

\subsubsection{Building the Interfacial Molecular System}

Schematic diagrams of the studied $\mathrm{Pt} / \mathrm{Pt}, \mathrm{Pt} / \mathrm{Ni}$ and $\mathrm{Si} / \mathrm{SiO}_{2}$ systems are given in Figure 6. The crystal structures of $\mathrm{Pt}$ [36], $\mathrm{Ni}$ [37], $\mathrm{Si}$, and $\mathrm{SiO}_{2}$ [39] are used to build the interfaces. For Si the bc8 form given by Kasper et al. [38] is used, and we used the cristobalite $\mathrm{SiO}_{2}$ of Nieuwenkamp et al., these two where specifically chosen to closely match each-others crystal lattice. The top and bottom sections $\left(9 \times 9 \times 6 \mathrm{Pt}, 10 \times 10 \times 6 \mathrm{Ni}, 3 \times 3 \times 2 \mathrm{Si}\right.$ and $\left.4 \times 4 \times 2 \mathrm{SiO}_{2}\right)$, are attached to strongly coupled thermostats ( $\tau=100 \mathrm{fs})$ and act as a heat source and heat sink. The intermediate regions $(9 \times 9 \times 9 \mathrm{Pt}$, $10 \times 10 \times 10 \mathrm{Ni}, 3 \times 3 \times 25 \mathrm{Si}$ and $\left.4 \times 4 \times 24 \mathrm{SiO}_{2}\right)$ are weakly coupled $\left(\tau=10^{5} \mathrm{fs}\right)$. The supercells are initially placed at a small distance and approach each other during an energy minimization to form the interface. From these energy minimized (merged) systems, the simulations are started. In the non-reactive systems, the top sections are kept at $T_{H}=330 \mathrm{~K}$ and bottom sections are kept at $T_{C}=300 \mathrm{~K}$. In the reactive systems temperature values are varied to trigger a chemical reaction at the interface. To calculate the TBR, all the simulations are done over $1 \mathrm{~ns}$, from which the last $0.75 \mathrm{~ns}$ are considered to obtain the data.

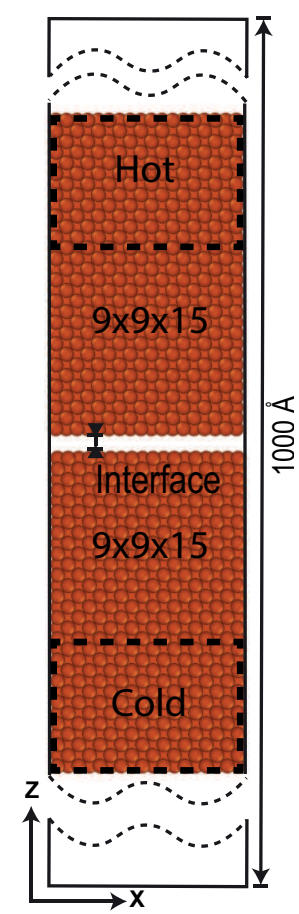

(a)

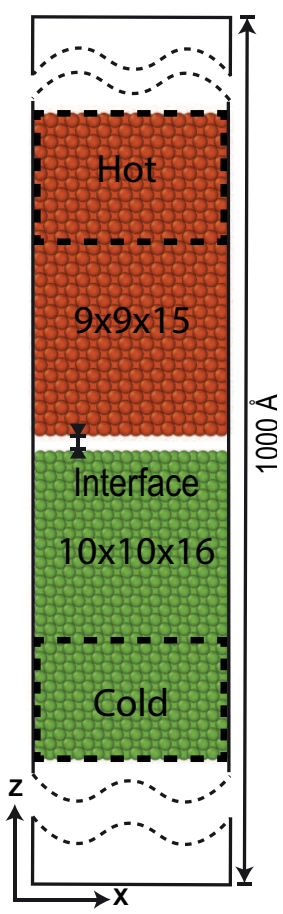

(b)

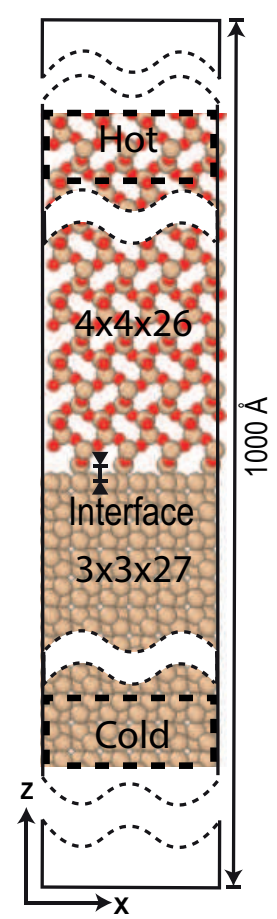

(c)

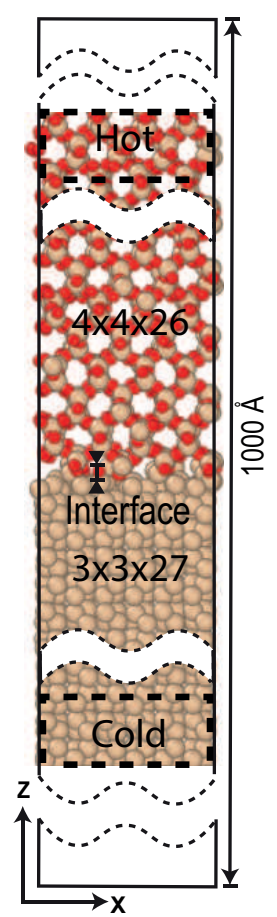

(d)

Figure 6. Schematic representation of systems: (a) non-reactive $\mathrm{Pt} / \mathrm{Pt}$ interface, (b) non-reactive $\mathrm{Pt} / \mathrm{Ni}$ interface, (c) initial reactive $\mathrm{Si} / \mathrm{SiO}_{2}$ interface, and (d) the merged reactive $\mathrm{Si} / \mathrm{SiO}_{2}$ interface. The particles in the dashed area are the strongly coupled sections, which acts as a heat source and heat sink. 
When an interface between two different materials is created artificial mechanical stresses are introduced by fitting the different lattice constants in one single periodic box. To restrict this to a minimum we carefully selected the materials, supercells, and orientation to create the interface. Thereby, the deformation of the crystals is limited to $0.1 \%$ compared to their literature value. Furthermore, we studied the influence of $1 \%$ deformation of Platinum on the thermal conductivity. The thermal conductivity for a compressed, as well as, a stretched crystal was lower, however for both cases within the standard deviation of the original system. The deformation of the crystals, and the study towards the thermal conductivity can be found in Appendix C.

\section{Results}

ReaxFF MD simulations are carried out to understand the temperature discontinuity across the solid interfaces of homogeneous $(\mathrm{Pt} / \mathrm{Pt})$, heterogeneous $(\mathrm{Pt} / \mathrm{Ni})$ and heterogeneous reactive materials $\left(\mathrm{Si} / \mathrm{SiO}_{2}\right)$. The computed material properties from the previous section are used to upscale the results from the molecular level to macroscopic phenomenological-theory level. For the thermal conductivity, the extrapolated value is used. A comparison is made between both methods for the non-reactive interfaces.

\subsection{Non-Reactive Interfaces}

In realistic experimental conditions, the thermostat takes time to set the desired temperature, thus the temperature of the heat source evolves with time. To study this effect on the final temperature profile in ReaxFF MD, we compared two different settings to increase the temperature of the heat source. One with a gradual temperature increase to $T_{H}$, and one with an instantaneously high temperature at $T_{H}$. See Appendix D, and Figure A1, for the result of the comparison between the two cases. We observe that the final temperature profile is almost the same for both cases. Thus in the following cases, we have initialized the temperature of the heat source instantaneously at high temperature (instant $\Delta T$ ).

For the non-reactive ReaxFF MD interface investigation, the systems given in Figure $6 a, b$ are studied. The temperature profile evolution across the solid interfaces of $\mathrm{Pt} / \mathrm{Pt}$ and $\mathrm{Pt} / \mathrm{Ni}$ systems with ReaxFF MD is plotted in gray-scale after every 200 ps, which can be seen in Figure 7a,b. The light-gray to black lines represents respectively the earlier and later time periods.
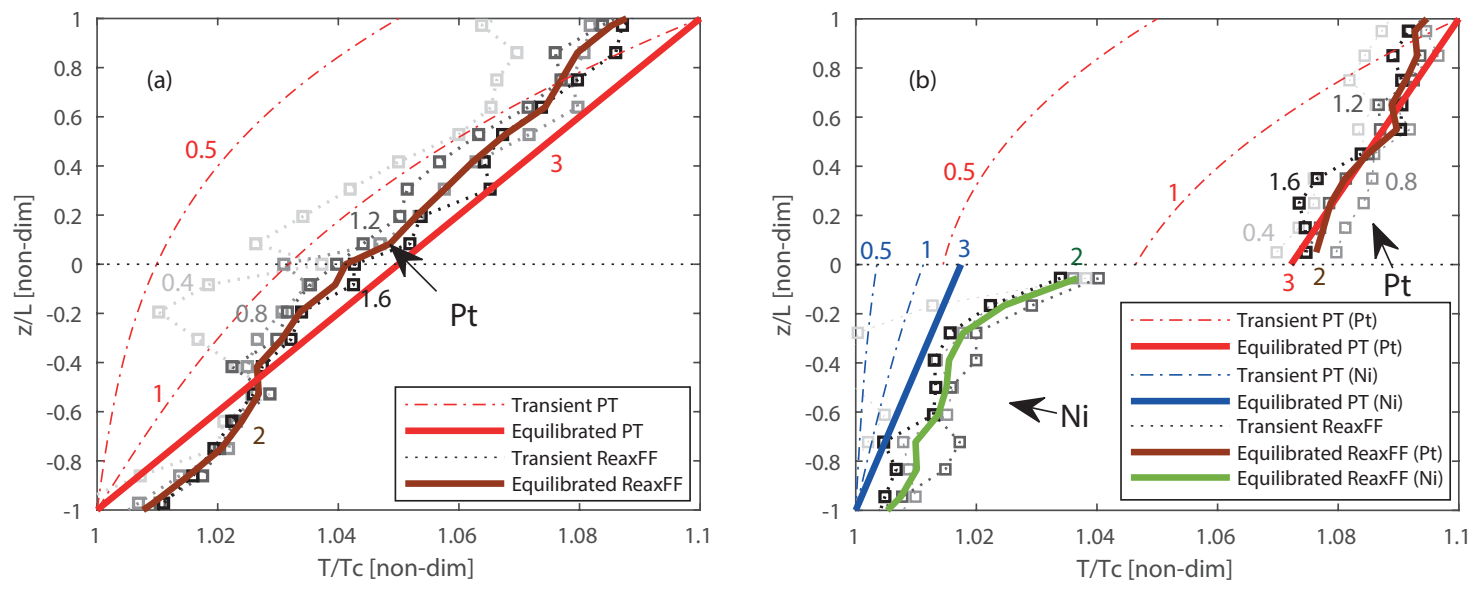

Figure 7. Comparison of temperature profile computed from PT based model and ReaxFF MD simulation for: (a) Pt/Pt interface. (b) Pt/Ni interfaces. The solid lines represent the equilibrated, and the dashed/dotted lines the transient temperature profiles. The dashed-dotted lines are intermediate transient temperature profiles for PT, and the dotted lines with square markers represent intermediates from ReaxFF MD simulations. The corresponding numbers at the lines represent $t_{\text {non-dim }}$. 
The equilibrated temperature is represented by the solid brown and green lines, respectively Platinum and Nickel. The temperature profiles developed over time obtained from ReaxFF MD are compared with the temperature profile from phenomenological-theory as shown in Figure 7. The molecular level ReaxFF MD simulations and macroscopic level phenomenological-theory have a different time scale, thus to compare them, a non-dimensional time ( $\left.t_{\text {non-dim }}\right)$ is defined as:

$$
t_{\text {non-dim }}=t / t_{e q}
$$

where $t$ is the actual time and $t_{e q}$ is the time assumed the system is in steady state. An steady state time of $0.5 \mathrm{~ns}$ is assumed for the MD simulations. The red, blue and gray numbers in the figures represent these different transient $t_{\text {non-dim }}$ states. The temperature profile obtained from the phenomenological-theory evolves slowly with time when compared with the ReaxFF MD simulations, where the transient states are quickly converging and fluctuation around the equilibrium state. In the ReaxFF MD results, a continuous temperature profile is observed at the $\mathrm{Pt} / \mathrm{Pt}$ interface while a temperature jump (discontinuity) is observed at the $\mathrm{Pt} / \mathrm{Ni}$ interface as shown in Figure 7a,b, respectively. Similar temperature profiles are also observed from the phenomenological-theory. The ReaxFF MD method shows a temperature jump of approximately $39 \%$, where the phenomenological-theory results in a $55 \%$ jump of the imposed temperature difference of $30 \mathrm{~K}$. Since one method is based on molecular level and another one is based on macroscopic level theory, a slight discrepancy in the magnitude of the temperature jump can be expected. These results confirm that the temperature jump is observed at the solid interface between different materials for both molecular level and macroscopic level modeling.

\subsection{Reactive Interfaces}

At the surface of re-entry vehicles chemical reactions can occur, these reactions contribute to the heating of such vehicles $[8,19]$. Furthermore, these reactions form a small layer, and influence the heat and mass transport at the surface. To gain more fundamental knowledge of such a surface, we studied a reactive solid $\mathrm{Si} / \mathrm{SiO}_{2}$ interface (see Figure $6 \mathrm{c}, \mathrm{d}$ ). The building of the physical system is similar to the two previous systems ( $\mathrm{Pt} / \mathrm{Pt}$ and $\mathrm{Pt} / \mathrm{Ni})$. The length between the heat source and sink is approximately $327 \AA$, and temperatures of the heat source and sink are varied to increase/decrease the chemical reaction at the solid interface [61]. Four different cases are studied, for the first case (Case 1) the set temperatures for heat source $\left(T_{H}\right)$ and sink $\left(T_{C}\right)$ are 150 and $100 \mathrm{~K}$, respectively. For the second case (Case 2), the temperatures are $T_{H}=350 \mathrm{~K}$ and $T_{C}=300 \mathrm{~K}$, and for the third case (Case 3) the temperatures are $T_{H}=850 \mathrm{~K}$ and $T_{C}=800 \mathrm{~K}$. These cases have an interface temperatures of approximately 125,325 , and $825 \mathrm{~K}$. In the fourth case (Case 4 ) the complete system was heated to a high temperature $(1700 \mathrm{~K})$ for $3.5 \mathrm{~ns}$ to create a reactive region, and thereafter, cooled back to $T_{C}=100 \mathrm{~K}$, and $T_{H}=150 \mathrm{~K}$ to stop the chemical activity completely again. After the cooling, a new steady state simulation was done at $T_{C}=100 \mathrm{~K}$, and $T_{H}=150 \mathrm{~K}$. From Figure A2 in Appendix E, one can see that the major part of the interface formation takes place within the first nanosecond. In terms the thickness of the interface, as well as, the depth of the oxygen penetration into the silicon surface only little changes are observed after the first nanosecond. Therefore, it was not needed to go for longer simulations to create the interface. This fourth case was chosen to get a distinct comparison between the non-reacted and reacted interface, at the same temperature (Case 1 and 4).

The resulted temperature profiles for Case 1-3 are plotted in Figure 8a. The temperature is made non-dimensional by taking $100-150 \mathrm{~K}$ as reference and divide by 100 . The thick solid lines are fitted to the data, and extrapolated to the interface, to get the temperature jump. The initial interface is positioned at $z=0 \AA$ in the figures. A temperature jump is observed between $\mathrm{Si}$ and $\mathrm{SiO}_{2}$ for all the cases. It reiterates that there is a temperature discontinuity at the reactive heterogeneous solid interface as well. Case $1(100-150 \mathrm{~K})$ shows a clear jump, with a sharp temperature profile. When the temperature is increased to $300-350 \mathrm{~K}$ (case 2), the jump remains, however, it is less sharp. This is 
caused by some small deformation at the interface induced by the temperature. Moving to even higher temperatures 800-850 K (case 3), not only a temperature jump but also a drop of the temperature profile over the entire system is observed. This suggests a heat sink at the interface, due to energy consumption by the deformation of the crystals at the interface. This deformation has an impact on the heat transfer and results in an intermediate region between the Silicon and Silica crystals of a few ångströms.
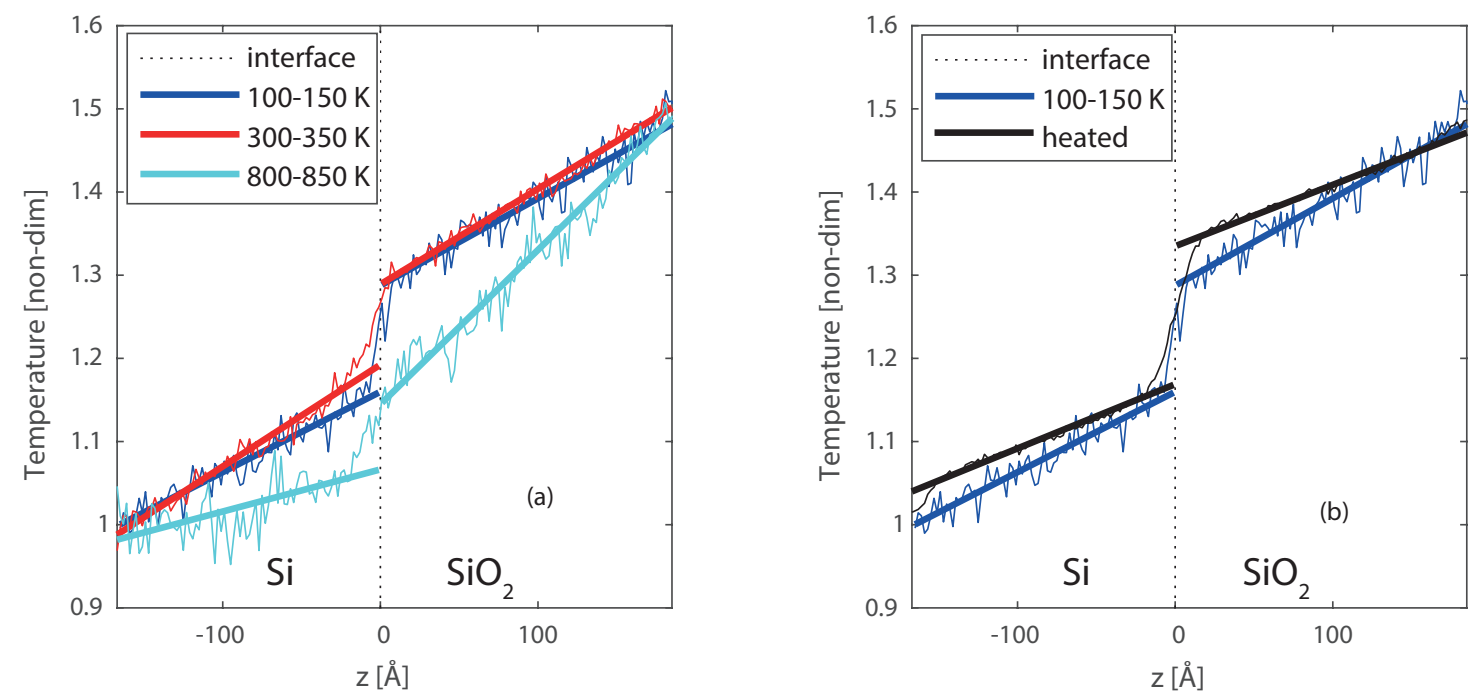

Figure 8. Temperature profiles for the $\mathrm{Si} / \mathrm{SiO}_{2}$ interfaces, with (a) case 1 , case 2 , and case 3 , and (b) case 1 , and case 4 . The dotted line indicates the location of the interface, the dark blue lines represent case $1\left(T_{H}=150\right.$ and $\left.T_{C}=100 \mathrm{~K}\right)$, the red lines represent case $2\left(T_{H}=350\right.$ and $\left.T_{C}=300 \mathrm{~K}\right)$, the light blue lines represent case $3\left(T_{H}=850\right.$ and $\left.T_{C}=800 \mathrm{~K}\right)$, and the black line represents case 4 (first heated to $1700 \mathrm{~K}$, and then a steady state at $T_{H}=150$ and $\left.T_{C}=100 \mathrm{~K}\right)$.

To better study the effect and size of the intermediate region, the entire $\mathrm{Si} / \mathrm{SiO}_{2}$ system was heated up to $1700 \mathrm{~K}$ to increase the reactivity and advance the formation of the intermediate region. Higher temperatures were also tested, however, these resulted in melting of the Silicon crystal, and separation of the two slabs. Lower temperatures would require more time to create a similar intermediate region. The heating process results in a larger intermediate amorphous region, where oxygen diffused up to $5 \AA$ into the Silicon crystal, and deformation of both materials is visible up to $10 \AA$ from the interface. After the heating, the system was cooled back to 100-150 K, this temperature was chosen to stop the chemical activity as far as possible. The final equilibrated temperature profile is compared with the temperature profile of case 1, where no reactive region is had been present at the interface. This comparison shown in Figure $8 b$, and a closer profile around the interface is shown in Figure 9a-c. From Figure 9c, the thicker interfacial region for the reacted interface can be clearly observed, compared to the non-reacted clean interface (Figure 9b). For the heated interface (case 4), the temperature jump $(\Delta T)$ is larger, however, is has become less sharp than case 1 and smoothed over the formed intermediate region.

The thermal boundary resistances (TBR) are given in Table 3. The calculated value for the low temperature (case 1) is in good agreement with Deng et al. [12], who found a value of $1.48( \pm 0.46) \times 10^{-9} \mathrm{~m}^{2} \mathrm{~K} / \mathrm{W}$ using NEMD, and $1.37( \pm 0.42) \times 10^{-9} \mathrm{~m}^{2} \mathrm{~K} / \mathrm{W}$ using phonon wave-package dynamics approach. The higher temperatures (case 2,3 ) approach the experimental results of Hurley et al. [21], who measured a resistance of $2.3 \times 10^{-9} \mathrm{~m}^{2} \mathrm{~K} / \mathrm{W}$. The reacted interface, which includes an amorphous $\mathrm{SiO}_{2}$ region, is in good agreement with the DMM results of Hu et al.[22], who found a resistance of $3.5 \times 10^{-9} \mathrm{~m}^{2} \mathrm{~K} / \mathrm{W}$, for amorphous $\mathrm{SiO}_{2}$ with $\mathrm{Si}$. The temperature jump at the interface for the 300-350 K and 800-850 K temperatures (case 2,3) is smaller, however, the calculated TBR is higher, caused by the deformation of the interface which acts as an extra heat sink. The TBR for 
the reacted interface (case 4) is more than twice the TBR of the non-reacted clean interface (case 1) at the same temperature, caused by the amorphous $\mathrm{Si}-\mathrm{SiO}_{2}$ intermediate region.
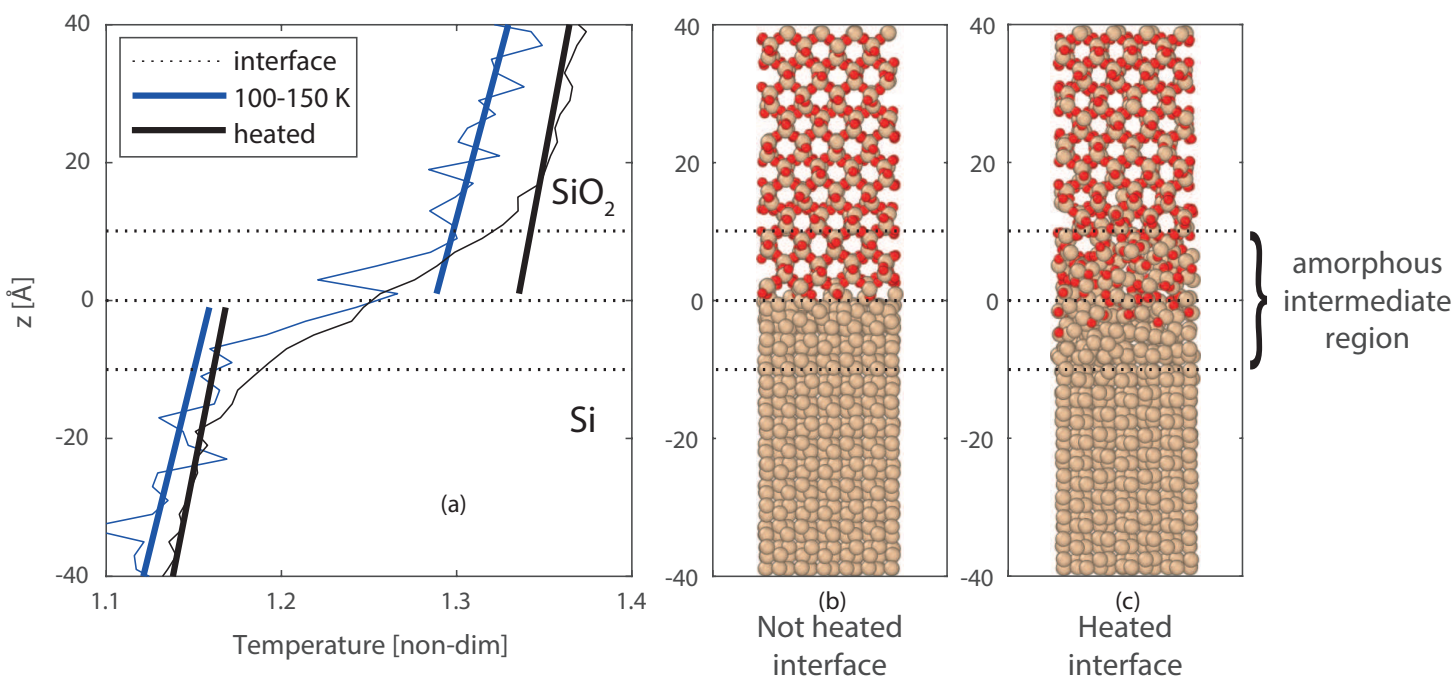

Figure 9. (a) zoom of Figure $8 \mathrm{~b}$, with the temperature profiles for case $1\left(T_{H}=150\right.$ and $\left.T_{C}=100 \mathrm{~K}\right)$, and case 4 (first heated to $1700 \mathrm{~K}$, and then a steady state at $T_{H}=150$ and $T_{C}=100 \mathrm{~K}$ ). The final molecular structures of the interfaces are given in (b) for case 1, and (c) for case 4 .

Table 3. Thermal Boundary Resistance (TBR) of $\mathrm{Si} / \mathrm{SiO}_{2}$ systems, with $T_{C}$ and $T_{H}(\mathrm{~K})$ as thermostatted temperature for the heat sink and source respectively.

\begin{tabular}{ccccc}
\hline Case & $\boldsymbol{T}_{\boldsymbol{C}}(\mathbf{K})$ & $\boldsymbol{T}_{\boldsymbol{H}} \mathbf{( K )}$ & Temperature Jump, $\boldsymbol{\Delta} \boldsymbol{T}(\mathbf{K})$ & $\mathbf{T B R}\left(\frac{\mathbf{m}^{\mathbf{2}} \mathbf{K}}{\mathbf{W}}\right)$ \\
\hline 1 & 100 & 150 & 12.8 & $1.65 \times 10^{-9}$ \\
2 & 300 & 350 & 9.7 & $2.40 \times 10^{-9}$ \\
3 & 800 & 850 & 7.8 & $2.34 \times 10^{-9}$ \\
4 & $1700 \rightarrow 100$ & $1700 \rightarrow 150$ & 16.6 & $3.38 \times 10^{-9}$ \\
\hline
\end{tabular}

\section{Conclusions}

ReaxFF MD is known to capture the physical and chemical phenomena under various conditions $[18,26]$. We have chosen various force fields for $\mathrm{Pt} / \mathrm{Ni}$ and $\mathrm{Si} / \mathrm{SiO}_{2}$ systems, which can mimic their material properties. The selected force fields predict the equilibrium volumes [36-39] and bulk modulus $[44,45,47,48]$ of respectively $\mathrm{Pt}, \mathrm{Ni}, \mathrm{Si}$ and $\mathrm{SiO}_{2}$ in close agreement with experiments/theory. To validate further, thermal expansion and thermal conductivity coefficients of $\mathrm{Pt}$ and $\mathrm{Ni}$ are estimated using ReaxFF MD. The thermal expansion coefficients are found to be in reasonable agreement with experiments. The thermal conductivity of a solid material is size-dependent on the molecular level. Thus, we have obtained the thermal conductivity of $\mathrm{Pt}$ and Ni for various system sizes and extrapolated to a very long length to determine the bulk thermal conductivity.

The elastic and thermal properties, obtained from ReaxFF MD, served as input parameters for the macroscopic level phenomenological-theory (PT) [8]. Temperature profiles of non-reactive interfaces, obtained from both methods, are compared. In this comparison, we have reported the temperature profiles across a homogeneous $(\mathrm{Pt} / \mathrm{Pt})$, and heterogeneous $(\mathrm{Pt} / \mathrm{Ni})$ interface. Temperature continuity is observed at the solid homogeneous interface of $\mathrm{Pt} / \mathrm{Pt}$. The temperature profile of the molecular level simulation is faster at equilibrium than the phenomenological-theory. The temperature profiles between $\mathrm{Pt} / \mathrm{Ni}$ has a discontinuity at the interface observed in both molecular and macroscopic level. The temperature jump obtained from the molecular level calculation is $18 \%$ lower than the one obtained from PT calculations. The discrepancy between the two models in the temperature jump for $\mathrm{Pt} / \mathrm{Ni}$ is minimal, and can be explained by the fact that the length- and time-scale for both calculations 
are different, and/or the length dependence of the thermal conductivity. We can conclude that both models, the molecular level ReaxFF MD simulations and the PT, predict a temperature discontinuity across the solid boundary if the materials are not the same.

The ReaxFF MD methodology can capture chemical reactions, therefore, interesting insights could be obtained for solid pairs which can form a reactive interface. For this purpose, the $\mathrm{Si} / \mathrm{SiO}_{2}$ pair was chosen and the heat source and heat sink were varied to increase/decrease the chemical reaction at the interface. Three distinct solids $\left(\mathrm{Si}\right.$, amorphous reacted $\mathrm{Si}-\mathrm{SiO}_{2}$ interface, and $\mathrm{SiO}_{2}$ ) have been observed. The thermal boundary resistance (TBR) is computed at the $\mathrm{Si} / \mathrm{SiO}_{2}$ interface for the different systems, providing us with information of the TBR over interfaces with different chemical activity. It can be concluded that the reacted amorphous region at the interface introduces extra resistivity, compared to the non-reactive clean interface. Showing the opportunity to control the thermal resistivity of a multi-layered system by controlling the interfacial reactive regions.

Author Contributions: Conceptualization, S.N. and D.G.; methodology, S.N. and D.G.; validation, K.H., A.P. and P.S.; investigation, K.H., A.P. and P.S.; resources, D.S.; writing-original draft preparation, K.H., A.P. and S.N.; writing-review and editing, K.H., A.P., S.N., P.S., D.G. and D.S.; supervision, S.N., D.G. and D.S.; funding acquisition, D.S

Funding: This research received no external funding.

Acknowledgments: The authors would like to thank the Netherlands Organization for Scientific Research (NWO) for access to the national high performance computing facilities (Dossiernr: 17092 6026).

Conflicts of Interest: The authors declare no conflict of interest.

\section{Appendix A. Birch-Murnaghan Equation of State Fitting $\mathrm{Si} \& \mathrm{SiO}_{2}$}

To select the correct force field, a BM-EOS study is done. The results of the fitting are presented in Table A1, with $r^{2}$ as correlation coefficient of the fitting. The results are compared with literature, which gives $V_{0, \mathrm{Pt}}=60.38 \AA^{3}$ [36], $V_{0, \mathrm{Ni}}=43.76 \AA^{3}$ [37], $V_{0, \mathrm{Si}}=292 \AA^{3}$ [38], $V_{0, \mathrm{SiO}_{2}}=171 \AA^{3}$ [39], $B_{0, \mathrm{Pt}}=266 \mathrm{GPa}$ [44], $B_{0, \mathrm{Ni}}=185 \mathrm{GPa}$ [45], $B_{0, \mathrm{Si}}=98 \mathrm{GPa}$ [62], and $B_{0, \mathrm{SiO}_{2}}=36 \mathrm{GPa}$ [48]. The ReaxFF of Mueller et al. [4] and Kulkarni et al. [19] proves to be the best applicable for respectively the Pt/Ni system and the $\mathrm{Si} / \mathrm{SiO}_{2}$ system.

Table A1. Results of BM-eos fitting to different ReaxFF.

\begin{tabular}{|c|c|c|c|c|c|c|}
\hline & $\begin{array}{l}\text { Reference } \\
\text { Force Field }\end{array}$ & $\begin{array}{c}B_{0} \\
(\mathrm{GPa})\end{array}$ & $\begin{array}{c}V_{0} \\
\left(\AA^{3}\right)\end{array}$ & $\begin{array}{c}E_{0} \\
\text { (kcal/mol) }\end{array}$ & $r^{2}$ & Figure \\
\hline \multirow[t]{3}{*}{$\mathrm{Pt}$} & {$[4]$} & 240 & 61.52 & -532.4 & 1.0 & Figure 2a L1 \\
\hline & [40] & 179 & 62.91 & -534.3 & 1.0 & Figure 2a L2 \\
\hline & [29] & 166 & 64.52 & -560.6 & 1.0 & Figure 2a L3 \\
\hline \multirow[t]{2}{*}{$\mathrm{Ni}$} & [4] & 155 & 46.96 & -414.9 & 1.0 & Figure $2 b$ L2 \\
\hline & [29] & 167 & 48.21 & -369.8 & 1.0 & Figure $2 b$ L1 \\
\hline \multirow[t]{9}{*}{$\mathrm{Si}$} & [19] & 144 & 272.1 & -1617 & 0.92 & Figure $2 c$ \\
\hline & [30] & 165 & 273.6 & -1611 & 0.88 & \\
\hline & [31] & 292 & 252.9 & -1729 & 0.95 & \\
\hline & [35] & 216 & 291.2 & -1675 & 0.53 & \\
\hline & [29] & 295 & 265.7 & -2244 & 0.84 & \\
\hline & [63] & 235 & 268.3 & -2206 & 0.95 & \\
\hline & [34] & 334 & 255.2 & -1728 & 0.95 & \\
\hline & [33] & 289 & 252.3 & -1730 & 0.95 & \\
\hline & [32] & 334 & 255 & -1728 & 0.95 & \\
\hline
\end{tabular}


Table A1. Cont.

\begin{tabular}{ccccccc}
\hline & $\begin{array}{c}\text { Reference } \\
\text { Force Field }\end{array}$ & $\begin{array}{c}\boldsymbol{B}_{\mathbf{0}} \\
(\mathbf{G P a})\end{array}$ & $\begin{array}{c}\boldsymbol{V}_{\mathbf{0}} \\
\left(\AA^{\mathbf{3}}\right)\end{array}$ & $\begin{array}{c}\boldsymbol{E}_{\mathbf{0}} \\
(\mathbf{k c a l} / \mathbf{m o l})\end{array}$ & $\boldsymbol{r}^{\mathbf{2}}$ & Figure \\
\hline $\mathrm{SiO}_{2}$ & {$[19]$} & 35 & 242.1 & -2128 & 0.83 & Figure 2d \\
& {$[30]$} & 500 & 244.6 & -1847 & 0.60 & \\
& {$[31]$} & 33 & 260.0 & -1818.6 & 0.86 & \\
& {$[35]$} & 34 & 238.1 & -1793 & 0.98 & \\
& {$[29]$} & 47 & 244.7 & -1860 & 0.83 & \\
{$[63]$} & 234 & 247.2 & -1828 & 0.78 & \\
& {$[34]$} & 331 & 263.4 & -1841 & 0.19 & \\
& {$[33]$} & 273 & 258.1 & -1837 & 0.16 & \\
& {$[32]$} & 331 & 263.4 & -1840 & 0.19 & \\
\hline
\end{tabular}

\section{Appendix B. Finite Size Effects, Perpendicular to the Heat Flow}

Platinum systems $(3 \times 3 \times 32,5 \times 5 \times 32,10 \times 10 \times 32)$ were used to study the finite size effects in perpendicular direction to the heat flow. The system are placed in vacuum in $z$-direction and have periodic boundary conditions in $\mathrm{x}$ - and $\mathrm{y}$-direction, the given crystal sizes are including heat source and sink. No final size effects are observed in perpendicular direction to the heat flow.

Table A2. Thermal conductivity of Pt-systems in vacuum in z-direction, and different sizes in $x$ and y-direction.

\begin{tabular}{cc}
\hline System & Thermal Conductivity (W/mK) \\
\hline $3 \times 3 \times 32$ & 9.7 \\
$5 \times 5 \times 32$ & 8.0 \\
$10 \times 10 \times 32$ & 10.7 \\
\hline
\end{tabular}

\section{Appendix C. Influence of Mechanical Deformation of Slabs}

When a heterogeneous interface with two different materials, and thus different lattice parameters, is created the materials are compressed or stretched to fit both materials within the same periodic box. This introduces extra mechanical stresses in the crystals. To restrict this to a minimum we have chosen the materials and supercells in such a way that these artificial deformations are kept to a minimum. The lattice parameters are given in Tables A3 and A4 for the literature value, after an energy minimization in ReaxFF, after an energy minimization in ReaxFF with a vacuum in $\mathrm{z}$ direction, and the size used in this work. The lattice parameters are compared with the literature value and the error is given in the last column, this shows that the values are all within $3 \%$, and there is only $0.1 \%$ deformation in this work compared to the lattice from literature.

Table A3. Lattice constant for Pt and Ni.

\begin{tabular}{ccc}
\hline System & Lattice [a; b; c] (̊̊) & Deviation from Literature (\%) \\
\hline Pt-literature [36] & $3.9231 ; 3.9231 ; 3.9231$ & - \\
Pt-EM ReaxFF & $3.9473 ; 3.9473 ; 3.9473$ & +0.6 \\
Pt-EM ReaxFF + vacuum in z-direction & $3.9412 ; 3.9412 ;-$ & +0.5 \\
Pt-interface & $3.9192 ; 3.9192 ;-$ & -0.1 \\
\hline Ni-literature [37] & $3.5238 ; 3.5238 ; 3.5238$ & - \\
Ni-EM ReaxFF & $3.6122 ; 3.6122 ; 3.6122$ & +2.5 \\
Ni-EM ReaxFF + vacuum in z-direction & $3.6048 ; 3.6048 ;-$ & +2.3 \\
Ni-interface & $3.5273 ; 3.5273 ;-$ & +0.1 \\
\hline
\end{tabular}


Table A4. Lattice constant for $\mathrm{Si}(\mathrm{bc} 8)$, and cristobalite $\mathrm{SiO}_{2}$.

\begin{tabular}{|c|c|c|}
\hline System & Lattice $[a ; b ; c](\AA)$ & Deviation From Literature (\%) \\
\hline Si (bc8)-literature [38] & $6.636 ; 6.636 ; 6.636$ & - \\
\hline Si (bc8)-EM ReaxFF & $6.4393 ; 6.4393 ; 6.4393$ & -2.9 \\
\hline Si (bc8)-EM ReaxFF + vacuum in z-direction & $6.4383 ; 6.4046 ;-$ & $-2.9 ;-43.5$ \\
\hline Si (bc8)-interface & $6.6273 ; 6.6273 ;-$ & -0.1 \\
\hline $\mathrm{SiO}_{2}$-literature [39] & $4.964 ; 4.964 ; 6.920$ & - \\
\hline $\mathrm{SiO}_{2}$-EM ReaxFF & $5.0443 ; 5.0443 ; 7.0063$ & +1.0 \\
\hline $\mathrm{SiO}_{2}$-EM ReaxFF + vacuum in z-direction & $5.0443 ; 5.0443 ;-$ & +1.0 \\
\hline $\mathrm{SiO}_{2}$-interface & $4.9705 ; 4.9705 ;-$ & +0.1 \\
\hline
\end{tabular}

\section{Influence of Stress on Thermal Conductivity}

To form an interface with different materials, the materials are slightly stressed to match each other lattice constants. One of the two materials was slightly compressed, and the other one slightly stretched to form the interface. In the Tables A3 and A4 amount of deformation is shown for the materials used in this work, which are within $\pm 0.1 \%$. To gain more knowledge on the effect of these stresses on the heat transport across the material, we computed the thermal conductivity for $3 \times 3 \times 132$ Platinum structures with lattices corresponding to the literature value, $1 \%$ compressed structures, a $1 \%$ stretched structures. The computed thermal conductivities for the different deformation are given in Table A5, and are within each other's standard deviation. Thereby, we conclude that we can neglect the effect of stress in this study.

Table A5. Thermal conductivity of a $3 \times 3 \times 132$ Platinum structure under different mechanically induced stresses.

\begin{tabular}{cccc}
\hline Simulation & $\begin{array}{c}\text { No Stress } \\
\mathbf{k}(\mathbf{W} / \mathbf{m K})\end{array}$ & $\begin{array}{c}\mathbf{1 \%} \text { Compression } \\
\mathbf{k}(\mathbf{W} / \mathbf{m K})\end{array}$ & $\begin{array}{c}\mathbf{1 \%} \text { Stretched } \\
\mathbf{k}(\mathbf{W} / \mathbf{m K})\end{array}$ \\
\hline 1 & 15.2 & 14.6 & 13.4 \\
2 & 17.8 & 13.9 & 14.6 \\
3 & 16.7 & 15.3 & 17.4 \\
4 & 15.6 & 16.5 & 16.5 \\
\hline Average & $16.3 \pm 1.2$ & $15.1 \pm 1.1$ & $15.5 \pm 1.8$ \\
\hline
\end{tabular}

\section{Appendix D. Comparison of Gradual and Instant Induced Temperature}

In realistic experimental conditions, the thermostat takes time to set the desired temperature, thus the temperature of the heat source evolves with time. To investigate the effect of heating the systems on the final temperature distribution in ReaxFF-MD, we have compared a gradual temperature increase to $T_{H}$ and an instantaneously temperature at $T_{H}$. For the gradual temperature setting, we have increased the temperature of the heat source $\left(T_{H}=330 \mathrm{~K}\right)$ in the steps of $5 \mathrm{~K}$ per 0.1 million iterations $(25 \mathrm{ps})$. After 0.6 million iterations ( $150 \mathrm{ps})$, the temperature profile of the gradual temperature rise system is compared with the system in which temperature of hot zone was instantaneously set at $T_{H}=330 \mathrm{~K}$ (instant $\Delta T$ ) as shown in Figure A1, the comparison was done over a total range of 1 million iterations. We observe that the equilibrated temperature profile is almost the same for both cases. Thus in the following cases, we have initialized the temperature of the heat source instantaneously at high temperature (instant $\Delta T$ ). 


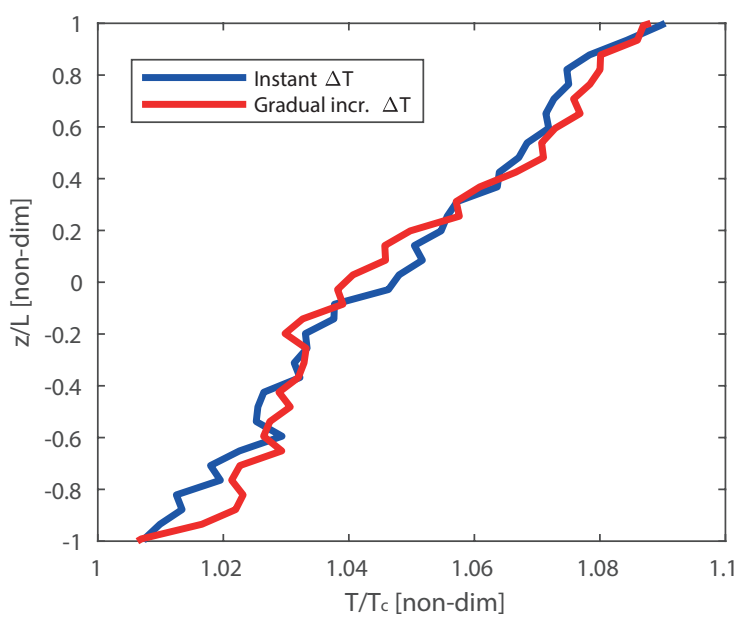

Figure A1. Comparison of temperature profiles (non-dim. T versus non-dim. $x$ ) obtained from ReaxFF-MD simulations for the Pt/Pt interface in the case where the heat source is immediately heated to $T_{H}=330 \mathrm{~K}$ (instant $\Delta T$ ) and system in which the heat source is gradually heated to $T_{H}=330 \mathrm{~K}$ in steps of $5 \mathrm{~K}$ per $1 \times 10^{5}$ iterations (gradual $\Delta T$ ).

\section{Appendix E. Development of the Amorphous $\mathrm{Si} / \mathrm{SiO}_{2}$ Interface}

To create a reactive formed interface between $\mathrm{Si}$ and $\mathrm{SiO}_{2}$, the system was heated for to high temperatures $(1700 \mathrm{~K})$ for $3.5 \mathrm{~ns}$. Thereafter, it was cooled back to $T_{C}=100 \mathrm{~K}$, and $T_{H}=150 \mathrm{~K}$ to stop the chemical activity completely again. The development of the interface over the first $3 \mathrm{~ns}$ can be observed in the snapshots in Figure A2, also the number of oxygen atoms are counted for these snapshots.

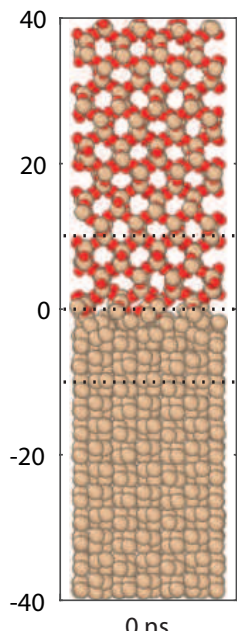

0 ns

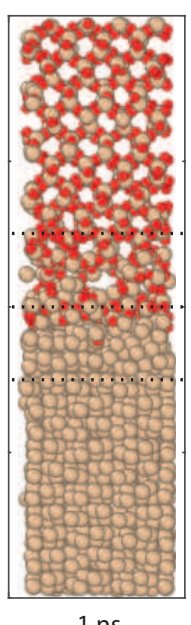

$1 \mathrm{~ns}$

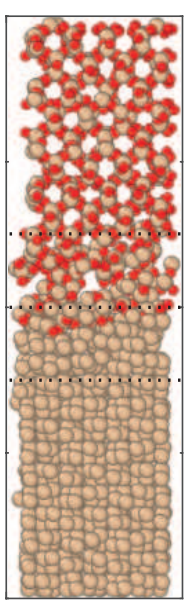

$2 \mathrm{~ns}$

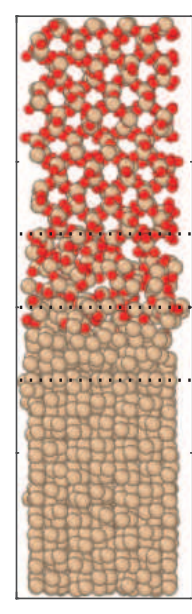

3 ns

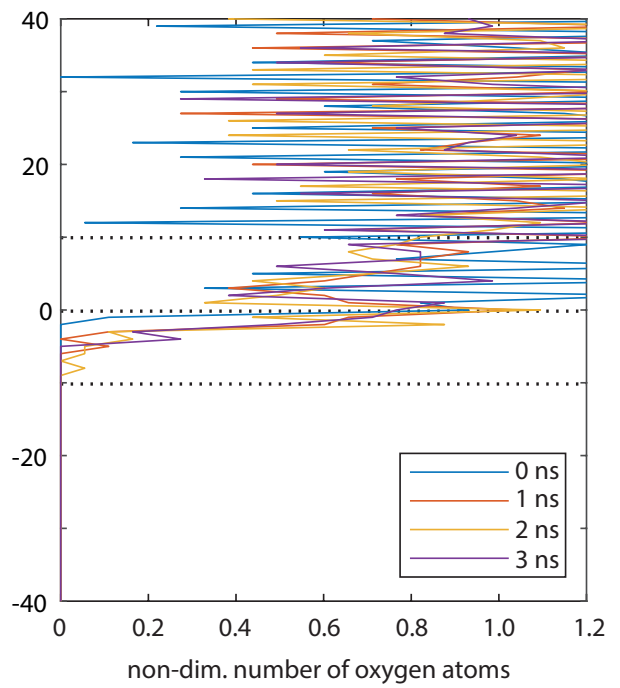

Figure A2. Snapshots of the $\mathrm{Si} / \mathrm{SiO}_{2}$ interface.

\section{References}

1. Samvedi, V.; Tomar, V. The role of interface thermal boundary resistance in the overall thermal conductivity of $\mathrm{Si}-\mathrm{Ge}$ multilayered structures. Nanotechnology 2009, 20, 365701. [CrossRef]

2. Pilania, G.; Thijsse, B.J.; Hoagland, R.G.; Lazić, I.; Valone, S.M.; Liu, X.Y. Revisiting the $\mathrm{Al} / \mathrm{Al}_{2} \mathrm{O}_{3}$ interface: Coherent interfaces and misfit accommodation. Sci. Rep. 2014, 4, 4485. [CrossRef] [PubMed]

3. Kim, J.; Frijns, A.J.H.; Nedea, S.V.; van Steenhoven, A.A. Molecular simulation of water vapor outgassing from silica nanopores. Microfluid. Nanofluid. 2015, 19, 565-576. [CrossRef] [PubMed] 
4. Mueller, J.E.; van Duin, A.C.T.; Goddard, W.A., III. Development and validation of ReaxFF reactive force field for hydrocarbon chemistry catalyzed by nickel. J. Phys. Chem. C 2010, 114, 4939-4949. [CrossRef]

5. Majumdar, A.S.M.E. Microscale heat conduction in dielectric thin films. J. Heat Transf. 1993, 115, 7-16. [CrossRef]

6. Schutze, J.; Ilgen, H.; Fahrner, W.R. An integrated micro cooling system for electronic circuits. IEEE Trans. Ind. Electron. 2001, 48, 281-285. [CrossRef]

7. Nunzi, F.; Sgamellotti, A.; Coletti, C.; Re, N. Adsorption and Interfacial Chemistry of Pentacene on the Clean Si(100) Surface: A Density Functional Study. J. Phys. Chem. C 2008, 112, 6033-6048. [CrossRef]

8. Giordano, D.; Solano-López, P.; Donoso, J.M. Exploratory numerical experiments with a macroscopic theory of interfacial interactions. CEAS Space J. 2017, 9, 257-277. [CrossRef]

9. Dias, B.; Bariselli, F.; Turchi, A.; Frezzotti, A.; Chatelain, P.; Magin, T. Development of a melting model for meteors. AIP Conf. Proc. 2016, 1786, 160004.

10. Merabia, S.; Termentzidis, K. Thermal conductance at the interface between crystals using equilibrium and nonequilibrium molecular dynamics. Phys. Rev. B 2012, 86, 094303. [CrossRef]

11. Mahajan, S.S.; Subbarayan, G.; Sammakia, B.G. Estimating Kapitza Resistance Between $\mathrm{Si}_{-} \mathrm{SiO}_{2}$ Interface Using Molecular Dynamics Simulations. IEEE Trans. Compon. Packag. Manuf. Technol. 2011, 1, 1132-1139. [CrossRef]

12. Deng, B.; Chernatynskiy, A.; Khafizov, M.; Hurley, D.H.; Phillpot, S.R. Kapitza resistance of Si/SiO 2 interface. J. Appl. Phys. 2014, 115, 084910.

13. Lampin, E.; Nguyen, Q.H.; Francioso, P.A.; Cleri, F. Thermal boundary resistance at silicon-silica interfaces by molecular dynamics simulations. Appl. Phys. Lett. 2012, 100, 131906. [CrossRef]

14. Chen, J.; Zhang, G.; Li, B. Thermal contact resistance across nanoscale silicon dioxide and silicon interface. J. Appl. Phys. 2012, 112, 064319. [CrossRef]

15. Zushi, T.; Ohmori, K.; Yamada, K.; Watanabe, T. Effect of a $\mathrm{SiO}_{2}$ layer on the thermal transport properties of $<100>$ Si nanowires: A molecular dynamics study. Phys. Rev. B 2015, 91, 115308.

16. Schelling, P.K.; Phillpot, S.R.; Keblinski, P. Comparison of atomic-level simulation methods for computing thermal conductivity. Phys. Rev. B 2002, 65, 144306. [CrossRef]

17. Van Duin, A.C.T.; Dasgupta, S.; Lorant, F.; Goddard, W.A. ReaxFF: A Reactive Force Field for Hydrocarbons. J. Phys. Chem. A 2001, 105, 9396-9409. [CrossRef]

18. Senftle, T.P.; Hong, S.; Islam, M.M.; Kylasa, S.B.; Zheng, Y.; Shin, Y.K.; Junkermeier, C.; Engel-Herbert, R.; Janik, M.J.; Aktulga, H.M.; others. The ReaxFF reactive force-field: Development, applications and future directions. NPJ Comput. Mater. 2016, 2, 15011. [CrossRef]

19. Kulkarni, A.D.; Truhlar, D.G.; Goverapet Srinivasan, S.; van Duin, A.C.T.; Norman, P.; Schwartzentruber, T.E. Oxygen interactions with silica surfaces: Coupled cluster and density functional investigation and the development of a new ReaxFF potential. J. Phys. Chem. C 2012, 117, 258-269. [CrossRef]

20. Van Duin, A.C.; Strachan, A.; Stewman, S.; Zhang, Q.; Xu, X.; Goddard, W.A. ReaxFFSiO reactive force field for silicon and silicon oxide systems. J. Phys. Chem. A 2003, 107, 3803-3811. [CrossRef]

21. Hurley, D.H.; Khafizov, M.; Shinde, S. Measurement of the Kapitza resistance across a bicrystal interface. J. Appl. Phys. 2011, 109, 083504. [CrossRef]

22. Hu, C.; Kiene, M.; Ho, P.S. Thermal conductivity and interfacial thermal resistance of polymeric low k films. Appl. Phys. Lett. 2001, 79, 4121-4123. [CrossRef]

23. Kapitza, P. Heat transfer and superfluidity of helium II. Phys. Rev. 1941, 60, 354. [CrossRef]

24. Peterson, R.; Anderson, A. The Kapitza thermal boundary resistance. J. Low Temp. Phys. 1973, 11, $639-665$. [CrossRef]

25. Frenkel, D.; Smit, B. Understanding Molecular Simulation: From Algorithms To Applications, 2nd ed.; Academic Press: Cambridge, MA, USA, 2001.

26. Pathak, A.D.; Nedea, S.; van Duin, A.C.T.; Zondag, H.; Rindt, C.; Smeulders, D. Reactive force field development for magnesium chloride hydrates and its application for seasonal heat storage. Phys. Chem. Chem. Phys. 2016, 18, 15838-15847. [CrossRef]

27. Kim, J.; Iype, E.; Frijns, A.J.; Nedea, S.V.; van Steenhoven, A.A. Development of EEM based silicon-water and silica-water wall potentials for non-reactive molecular dynamics simulations. J. Comput. Phys. 2014, 268, 51-62. [CrossRef] 
28. Suek, N.W.; Guillaume, M.C.; Delannoy, J.Y.P.; Tielens, F. Characterization of hydroxylated amorphous silica: A numerical approach. Adsorption 2018, 24, 267-278. [CrossRef]

29. Nielson, K.D.; van Duin, A.C.T.; Oxgaard, J.; Deng, W.Q.; Goddard, W.A., III. Development of the ReaxFF reactive force field for describing transition metal catalyzed reactions, with application to the initial stages of the catalytic formation of carbon nanotubes. J. Phys. Chem. A 2005, 109, 493-499. [CrossRef]

30. Fogarty, J.C.; Aktulga, H.M.; Grama, A.Y.; Van Duin, A.C.T.; Pandit, S.A. A reactive molecular dynamics simulation of the silica-water interface. J. Chem. Phys. 2010, 132, 174704. [CrossRef]

31. Narayanan, B.; van Duin, A.C.T.; Kappes, B.B.; Reimanis, I.E.; Ciobanu, C.V. A reactive force field for lithium-aluminum silicates with applications to eucryptite phases. Model. Simul. Mater. Sci. Eng. 2011, 20, 015002. [CrossRef]

32. Castro-Marcano, F.; van Duin, A.C.T. Comparison of thermal and catalytic cracking of 1-heptene from ReaxFF reactive molecular dynamics simulations. Combust. Flame 2013, 160, 766-775. [CrossRef]

33. Pitman, M.C.; Van Duin, A.C.T. Dynamics of confined reactive water in smectite clay-zeolite composites. J. Am. Chem. Soc. 2012, 134, 3042-3053. [CrossRef]

34. Zou, C.; Van Duin, A.C.T. Investigation of Complex Iron Surface Catalytic Chemistry Using the ReaxFF Reactive Force Field Method. JOM 2012, 64, 1426-1437. [CrossRef]

35. Newsome, D.A.; Sengupta, D.; Foroutan, H.; Russo, M.F.; van Duin, A.C.T. Oxidation of silicon carbide by $\mathrm{O}_{2}$ and $\mathrm{H}_{2} \mathrm{O}$ : A ReaxFF reactive molecular dynamics study, Part I. J. Phys. Chem. C 2012, 116, 16111-16121. [CrossRef]

36. Wyckoff, R.W. Crystal Structures; Interscience Publishers: New York, NY, USA, 1963; p. 1.

37. Swanson, H.E.; Tatge, E.; Fuyat, R.K. Standard X-ray Diffraction Powder Patterns; US Government Publishing Office: Washington, DC, USA, 1953.

38. Kasper, J.S.; Richards, S.M. The crystal structures of new forms of silicon and germanium. Acta Crystallogr. 1964, 17, 752-755. [CrossRef]

39. Nieuwenkamp, W. Die Kristallstruktur des Tief-Cristobalits $\mathrm{SiO}_{2}$. Z. Krist. Cryst. Mater. 1935, 92, 82-88. [CrossRef]

40. Sanz-Navarro, C.F.; Åstrand, P.O.; Chen, D.; Rønning, M.; van Duin, A.C.T.; Jacob, T.; Goddard, W.A. Molecular dynamics simulations of the interactions between platinum clusters and carbon platelets. J. Phys. Chem. A 2008, 112, 1392-1402. [CrossRef] [PubMed]

41. Murnaghan, F.D. The compressibility of media under extreme pressures. Proc. Natl. Acad. Sci. USA 1944, 30, 244-247. [CrossRef]

42. Birch, F. Finite strain isotherm and velocities for single-crystal and polycrystalline $\mathrm{NaCl}$ at high pressures and 300 K. J. Geophys. Res. Solid Earth 1978, 83, 1257-1268. [CrossRef]

43. Colonna, F.; Fasolino, A.; Meijer, E.J. High-pressure high-temperature equation of state of graphite from Monte Carlo simulations. Carbon 2011, 49, 364-368. [CrossRef]

44. Holmes, N.C.; Moriarty, J.A.; Gathers, G.R.; Nellis, W.J. The equation of state of platinum to 660 GPa (6.6 Mbar). J. Appl. Phys. 1989, 66, 2962-2967. [CrossRef]

45. Chen, B.; Penwell, D.; Kruger, M.B. The compressibility of nanocrystalline nickel. Solid State Commun. 2000, 115, 191-194. [CrossRef]

46. Tian, Y.; Du, J.; Han, W.; Zu, X.; Yuan, X.; Zheng, W. Thermal conductivity of vitreous silica from molecular dynamics simulations: The effects of force field, heat flux and system size. J. Chem. Phys. 2017, 146, 054504. [CrossRef] [PubMed]

47. Bernstein, N.; Mehl, M.J.; Papaconstantopoulos, D.A.; Papanicolaou, N.I.; Bazant, M.Z.; Kaxiras, E. Energetic, vibrational, and electronic properties of silicon using a nonorthogonal tight-binding model. Phys. Rev. B 2000, 62, 4477-4487. [CrossRef]

48. Liu, L. Bulk moduli of $\mathrm{SiO}_{2}$ polymorphs: Quartz, coesite and stishovite. Mech. Mater. 1993, 14, $283-290$. [CrossRef]

49. Mashreghi, A. Determining the volume thermal expansion coefficient of $\mathrm{TiO}_{2}$ nanoparticle by molecular dynamics simulation. Comput. Mater. Sci. 2012, 62, 60-64. [CrossRef]

50. Bolz, R.E. CRC Handbook of Tables for Applied Engineering Science; CRC Press:Boca Raton, FL, USA, 1973.

51. Kollie, T.G. Measurement of the thermal-expansion coefficient of nickel from 300 to $1000 \mathrm{~K}$ and determination of the power-law constants near the Curie temperature. Phys. Rev. B 1977, 16, 4872. [CrossRef] 
52. Chantrenne, P.; Barrat, J.L. Finite size effects in determination of thermal conductivities: Comparing molecular dynamics results with simple models. J. Heat Transf. 2004, 126, 577-585. [CrossRef]

53. Stackhouse, S.; Stixrude, L. Theoretical methods for calculating the lattice thermal conductivity of minerals. Rev. Mineral. Geochem. 2010, 71, 253-269. [CrossRef]

54. Zhou, X.W.; Aubry, S.; Jones, R.E.; Greenstein, A.; Schelling, P.K. Towards more accurate molecular dynamics calculation of thermal conductivity: Case study of GaN bulk crystals. Phys. Rev. B 2009, 79, 115201. [CrossRef]

55. Heino, P.; Ristolainen, E. Thermal conduction at the nanoscale in some metals by MD. Microelectron. J. 2003, 34, 773-777. [CrossRef]

56. Chen, G. Nanoscale Energy Transport and Conversion: A Parallel Treatment of Electrons, Molecules, Phonons, and Photons; Oxford University Press: Oxford, UK, 2005.

57. Dames, C.; Chen, G. Theoretical phonon thermal conductivity of Si/Ge superlattice nanowires. J. Appl. Phys. 2004, 95, 682-693. [CrossRef]

58. Lide, D.R. CRC Handbook of Chemistry and Physics; CRC Press: Boca Raton, FL, USA, 2003.

59. Berendsen, H.J.C. A Student's Guide to Data and Error Analysis; Cambridge University Press: Cambridge, UK, 2011.

60. Islam, M.M.; Kolesov, G.; Verstraelen, T.; Kaxiras, E.; van Duin, A.C. eReaxFF: A pseudoclassical treatment of explicit electrons within reactive force field simulations. J. Chem. Theory Comput. 2016, 12, 3463-3472. [CrossRef] [PubMed]

61. Tromp, R.; Rubloff, G.W.; Balk, P.; LeGoues, F.K.; van Loenen, E.J. High-Temperature $\mathrm{SiO}_{2}$ Decomposition at the $\mathrm{SiO}_{2} / \mathrm{Si}$ Interface. Phys. Rev. Lett. 1985, 55, 2332. [CrossRef] [PubMed]

62. Hopcroft, M.A.; Nix, W.D.; Kenny, T.W. What is the Young's Modulus of Silicon? J. Microelectromech. Syst. 2010, 19, 229-238. [CrossRef]

63. Rahnamoun, A.; van Duin, A.C.T. Reactive Molecular Dynamics Simulation on the Disintegration of Kapton, POSS Polyimide, Amorphous Silica, and Teflon during Atomic Oxygen Impact Using the Reaxff Reactive Force-Field Method. J. Phys. Chem. A 2014, 118, 2780-2787. [CrossRef]

(C) 2019 by the authors. Licensee MDPI, Basel, Switzerland. This article is an open access article distributed under the terms and conditions of the Creative Commons Attribution (CC BY) license (http:/ / creativecommons.org/licenses/by/4.0/). 